\title{
An Evaluation of Core Competence on Knowledge Management for Elementary Schools' Teachers: A Case Study of Remote Rural Area in Taiwan
}

\author{
Ya-Ching Yeh, Tzung-Hsien Huang, Chia-Chun Hsiao \\ Department of Education, National University of Tainan, Taiwan \\ yaching0315@yahoo.com
}

\begin{abstract}
In the knowledge economy era, teachers' core competencies for knowledge management have an important impact on the development of school education. It is an important issue to explore how to evaluate core competencies of knowledge management for elementary schools' teachers. This requires a thorough investigation to gain core competencies. Hence, the main purpose of this paper is to present a Matrix Analysis (MA) approach for evaluating core competencies of knowledge management and to describe the applications of the MA approach for elementary schools' teachers. An empirical analysis is performed to demonstrate the computational process of the MA approach adopted by this paper. Study results show that eleven core competencies are identified. They are 'finding problems,' 'flexibility,' 'interpersonal communication,' 'oral communication skills,' 'knowledge selection,' 'activities recording,' 'knowledge application on work planning,' 'research data application,' 'transforming knowledge into concrete actions,' 'interpreting results,' and 'judging knowledge value,' respectively. It is suggested that more attentions should be paid to exploit these core competencies effectively and then develop the solutions, which should continuously strengthen the perspective of teachers in order to obtain the competitive advantages in the future.
\end{abstract}

Keywords: Core competence, Knowledge management, Elementary school, Teacher

\section{Introduction}

In the past two decades, due to the constant environmental changes inside and outside the organization, the traditional economic production elements (capital, land, plant, machinery and equipment) are inadequate for the environmental changes. To enhance the competitiveness, the concepts such as knowledge and knowledge management, etc. should be introduced into the organization in a timely manner. And because of the addition of activities for knowledge value, the organizational performance and corporate competitiveness can be improved effectively. Thus the knowledge becomes one of the new economic production elements (Alavi and Leidner, 2001; Baldwin and Hanel, 2003; Kebede, 2010; Lee and Chen, 2012; Newell et al., 2002). Also, since every industry treats the knowledge management as an important management activity, the knowledge-based economy is thus established. 
School is a type of non-profit organization (NPO) (Jones and George, 2010). People who work in this type of organization coordinate their actions with each other to achieve a variety of goals. School education is a kind of service industry (Cheng, 2007); among which, the service providers (including the principal, teachers, administration employee and relevant technicians) and customers (including the students, students' parents, social people and enterprise sponsors) are two major entities. We understand that teachers are the most important adult educators in a school organization. Hu et al. (2006) as well as Hsiao and $\mathrm{Hu}$ (2007) considered that in the knowledge economy era, teachers' core competencies for knowledge management have an important impact on the development of school education. Because besides the traditional administrative or teaching capabilities, it is indeed an important subject for teachers to have plenty of core competencies for knowledge management in order to response to challenges in the knowledge economy era.

As currently the academic research on assessments of teachers' core competencies for knowledge management is much less, there are only four Chinese periodical literature of Hu et al. (2005a; 2005b; 2006) and Hsiao and Hu (2007) exploring core competencies of knowledge management for adult educators. Since there is the possibility and validity for further academic exploration on the topic of core competencies for knowledge management in Taiwan, thus it triggers the research motivation of this study. For measuring the core competencies of knowledge management for adult educators, school teachers in remote rural area are taken by this study as the research targets. To determine whether the concept of this study is sufficient to successfully operate, this study firstly plans to take indicators of teachers' core competencies for knowledge management as the assessment criteria. Due to the fact that the Grant's Matrix Analysis (MA) approach is simple to interpret and is easy to evaluate the core competences in this paper; hence, this paper intends to identify and summarize which are the core competencies of knowledge management valued by schools teachers through the empirical investigation. The next section presents the materials and methods. Consequently, a case study is surveyed. Finally, conclusions are made in the last section.

\section{Materials and Methods}

In this section, some of the concepts used in this paper are briefly introduced. These include the indicators of teachers' core competencies of knowledge management, and the Grant's MA approach.

The indicators of teachers' core competencies of knowledge management: Teachers are the main type of adult educators. It is very important that teachers know how to effectively face challenges in the knowledge economy era to improve their professionalism and competitiveness as well as core competencies needed for knowledge management ( $\mathrm{Hu}$ et al., 2006). In order to understand the connotation of indicators of adult educators' core competencies for knowledge management, this study refers to the index connotation of $\mathrm{Hu}$ et al (2006), to be as an important reference in following up 
assessments of teachers' core competencies for knowledge management.

$\mathrm{Hu}$ et al. (2006) believe that knowledge management is to carry out a series of activities in manage individual knowledge. And these activities include knowledge innovation, storage, dissemination, application, and evaluation. Therefore, this study adopts mainly these five aspects to explore adult educators' core competencies for knowledge management and they are described as below:

- Core competencies of knowledge innovation, including the abilities of (1) finding problems; (2) imagination; (3) examination; (4) flexibility; (5) conceptual naming; and (6) breaking stereotypes.

- Core competencies of knowledge dissemination, including the abilities of (1) multimedia usage; (2) public media usage; (3) understanding market demand; (4) knowledge sharing; (5) interpersonal communication; (6) curriculum design and event planning; (7) writing skills; and (8) oral communication skills.

- Core competencies of knowledge accumulation, including the abilities of (1) knowledge selection; (2) activities recording; (3) file management; (4) knowledge classification; (5) research methods and research data interpretation; and (6) creating knowledge database.

- Core competencies of knowledge application, including the abilities of (1) knowledge application on work planning; (2) knowledge application on solving problems; (3) research data application; (4) knowledge application on improving organization atmosphere; (5) knowledge application on resources development; (6) knowledge application on various circumstances; (7) transforming knowledge into concrete actions; and (8) knowledge application on creating substantial work pieces such as drafting proposals, drafting teaching plans, and publishing theses, etc.

- Core competencies of knowledge assessment, including the abilities of (1) using tools (including charts and tables); (2) interpreting results; (3) reviewing knowledge usefulness; (4) judging knowledge value; and (5) analyzing knowledge cost.

Grant's MA approach: For convenience and simplicity, we used the Grant's MA approach to evaluate the teachers' core competencies for knowledge management. A stepwise description of MA approach is given in the following.

Step 1: Assess the importance and relative strengths of each competence. Let $I_{j p}$ and $S_{j p}$, $j=1,2, \ldots, m, \quad p=1,2, \ldots, n$, be the importance value and relative strength, measured by Likert's 7-point scale, given to competence $j$ by DM $p$, respectively. It can be expressed as $1 \leq I_{j p} \leq 7$ and $1 \leq S_{j p} \leq 7$

Step 2: Use geometric mean technique (Saaty, 1980) to integrate the opinions of all DMs. Let $I_{j}$ and $S_{j}$ denote the consensus opinion evaluation value of the importance and relative strength of each 
competence, respectively. Then $I_{j}$ and $S_{j}$ can be represented by $I_{j}=\left(\prod_{p=1}^{n} I_{j p}\right)^{1 / n}$ and $S_{j}=\left(\prod_{p=1}^{n} S_{j p}\right)^{1 / n}$, respectively.

Step 3: Set up the threshold value (TV). In this paper, the TV of importance (i.e. first TV) and relative strength (i.e. second TV) of all questionnaires are calculated by the arithmetic mean of all $m$ competencies (Lu and $\mathrm{Wu}, 2010)$. That is, the first and second TVs are $\mu_{I}=\left(\sum_{j=1}^{m} I_{j}\right) / m \quad$ and $\mu_{S}=\left(\sum_{j=1}^{m} S_{j}\right) / m$, respectively.

Step 4: Skeletonize the relative position of all competencies shown as Figure 1. The figure is plotted in a two-dimensional matrix, which is composed by key strength (KS) zone, key weakness (KW) zone, superfluous strength (SS) zone, and zone of irrelevance (ZI). In this paper, we consider the core competencies are fallen into the KS zone.

Figure 1: Evaluating core competencies of knowledge management

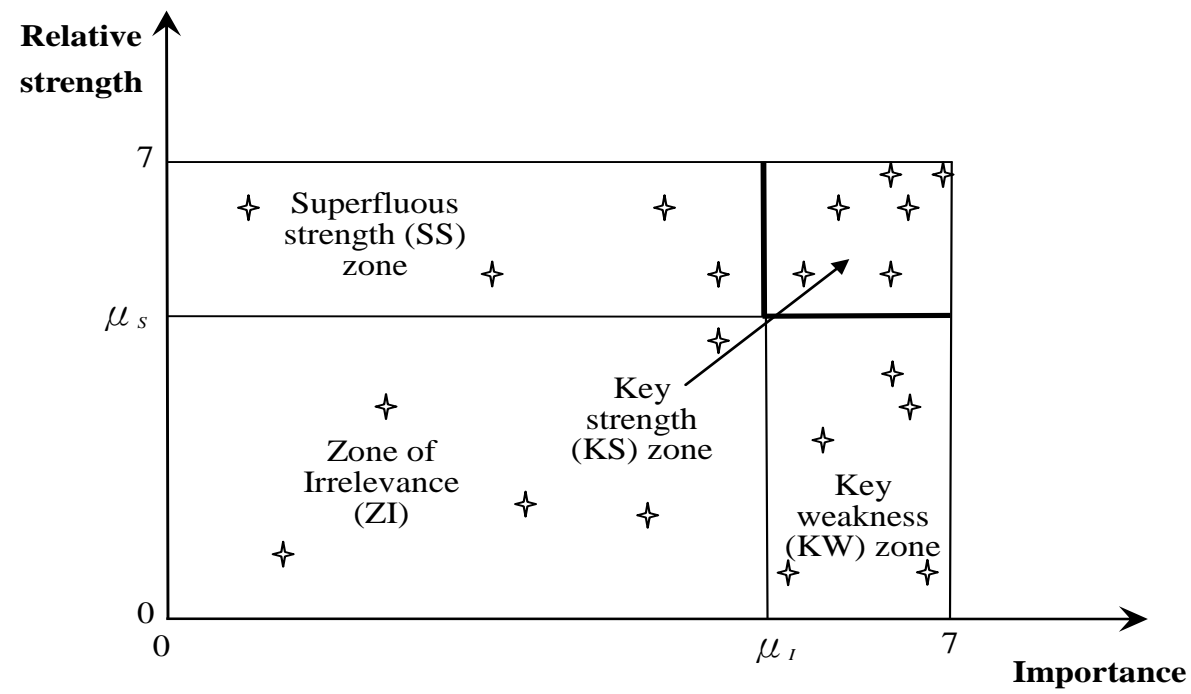

\section{Empirical Study}

In this section, questionnaire and data collection, result and discussions are described.

Questionnaire and data collection: In order to examine whether the 33 competencies are valued by the teachers of elementary schools at remote rural area in Taiwan, the data of five aspects and 33 competencies were collected via questionnaires, which were divided into two parts. Part I is related to the basic data; meanwhile the Part II measures the importance and relative strength of 33 competencies, which were based on a Likert 7-point scale, ranging from '1' for 'very unimportant' (strongly dissatisfied) to '7' for 'very important' (strongly satisfied). The questionnaire was filled in by the related teachers of elementary schools at remote rural area in Taiwan. In addition, the surveys were completed through e-mails, phone calls, and in-person interviews conducted by the authors. A total of 81 valid samples were 
collected from the 105 questionnaires, which represents $77.1 \%$ of the total questionnaires.

Table 1: Basic statistics data

\begin{tabular}{|c|c|c|c|}
\hline Item & Option & Frequency & Percentage (\%) \\
\hline \multirow[t]{2}{*}{ Gender } & - Male & 29 & 35.80 \\
\hline & - Female & 52 & 64.20 \\
\hline \multirow[t]{5}{*}{ Age (years old) } & $-21-30$ & 12 & 14.81 \\
\hline & $-31-40$ & 54 & 66.67 \\
\hline & $-41-50$ & 13 & 16.05 \\
\hline & $-51-60$ & 2 & 2.47 \\
\hline & $->65$ & 0 & 0 \\
\hline \multirow[t]{3}{*}{ Education } & - Bachelor or associate degree & 56 & 69.14 \\
\hline & - Master degree & 25 & 30.86 \\
\hline & - PhD degree & 0 & 0 \\
\hline \multirow[t]{6}{*}{ Seniority (years) } & $-1-5$ & 14 & 17.29 \\
\hline & $-6-10$ & 35 & 43.21 \\
\hline & $-11-15$ & 16 & 19.75 \\
\hline & $-16-20$ & 6 & 7.41 \\
\hline & $-21-25$ & 5 & 6.17 \\
\hline & $->25$ & 5 & 6.17 \\
\hline \multirow[t]{5}{*}{ Position } & - Teacher as well as department & 8 & 9.88 \\
\hline & head & & \\
\hline & - Teacher as well as group leader & 19 & 23.45 \\
\hline & - Grade school advisers & 45 & 55.56 \\
\hline & - Appointed teacher & 9 & 10.11 \\
\hline School size & $-1-6$ & 21 & 25.93 \\
\hline \multirow[t]{3}{*}{ (classes) } & $-7-12$ & 7 & 8.64 \\
\hline & $-13-18$ & 19 & 23.46 \\
\hline & - >18 & 34 & 41.97 \\
\hline
\end{tabular}

The reliability (Hair et al., 2010) of the article applies Cronbach's $\alpha$ to measure the consistency of all competencies covered in each aspect. If the coefficient of Cronbach's $\alpha$ falls higher than 0.7, it is a high value of reliability. After conducing reliability analysis, the importance and relative strength of all competencies were 0.841 and 0.864 , respectively, and it is therefore a high reliability value. Due to the fact that the questionnaire of this paper introduces questionnaires with literature or practical verifications collected by related experts, and hence the paper contains reasonable content validity (Hair et al., 2010). The basic statistics information can be shown in the Table 1. Finally, the summary of this questionnaire survey is shown as follows: 
- Females account for $64.20 \%$;

- Most participants are 31-40 years old (66.67\%);

- Most graduated from college or university (69.14\%);

- Most are employed 6-10 years (43.21\%), followed by $11-15$ years $(19.75 \%)$;

- Most are grade school advisers (55.56\%); and

- Most are over 18 classes of school size (41.97\%).

\section{Results and Discussion}

In this study, the results and processes of geometric means on the importance and relative strength are shown in Table 2.

Table 2: The MA results

\begin{tabular}{|c|c|c|c|}
\hline \multirow[b]{2}{*}{ Competence } & \multicolumn{2}{|c|}{ Geometric mean } & \multirow[b]{2}{*}{ Results } \\
\hline & Importance & $\begin{array}{l}\text { Relative } \\
\text { strength }\end{array}$ & \\
\hline Finding problems & 5.834 & 5.310 & KS \\
\hline Imagination & 4.882 & 4.839 & SS \\
\hline Examination & 5.961 & 4.578 & KW \\
\hline Flexibility & 5.851 & 5.229 & $\mathrm{KS}$ \\
\hline Conceptual naming & 5.589 & 4.564 & KW \\
\hline Breaking stereotypes & 6.021 & 4.637 & KW \\
\hline Multimedia usage & 4.753 & 4.943 & SS \\
\hline Public media usage & 4.647 & 4.318 & ZI \\
\hline Understanding market demand & 4.749 & 4.409 & $\mathrm{ZI}$ \\
\hline Knowledge sharing & 5.596 & 4.592 & KW \\
\hline Interpersonal communication & 5.877 & 5.114 & $\mathrm{KS}$ \\
\hline Curriculum design and event planning & 6.268 & 4.596 & KW \\
\hline Writing skills & 6.157 & 4.512 & KW \\
\hline Oral communication skills & 6.006 & 5.112 & KS \\
\hline Knowledge selection & 5.789 & 5.094 & KS \\
\hline Activities recording & 5.619 & 4.974 & KS \\
\hline File management & 5.973 & 4.474 & KW \\
\hline Knowledge classification & 5.932 & 4.442 & KW \\
\hline Research methods and research data interpretation & 5.928 & 4.416 & KW \\
\hline Creating knowledge database & 4.864 & 4.857 & SS \\
\hline Knowledge application on work planning & 5.489 & 5.124 & $\mathrm{KS}$ \\
\hline Knowledge application on solving problems & 5.961 & 4.543 & KW \\
\hline Research data application & 5.594 & 4.949 & KS \\
\hline
\end{tabular}




\begin{tabular}{|c|c|c|c|}
\hline knowledge application on improving organization atmosphere & 4.692 & 4.261 & ZI \\
\hline Knowledge application on resources development & 4.822 & 4.914 & SS \\
\hline Knowledge application on various circumstances & 4.892 & 4.398 & ZI \\
\hline Transforming knowledge into concrete actions & 5.876 & 5.141 & KS \\
\hline Knowledge application on creating substantial work pieces & 5.948 & 4.414 & KW \\
\hline Using tools & 5.899 & 4.461 & KW \\
\hline Interpreting results & 5.892 & 5.116 & KS \\
\hline Reviewing knowledge usefulness & 4.871 & 4.630 & ZI \\
\hline Judging knowledge value & 5.561 & 5.167 & KS \\
\hline Analyzing knowledge cost & 5.009 & 4.264 & ZI \\
\hline Average & 5.540 & 4.745 & \\
\hline
\end{tabular}

Note: The 'KS,' 'KW,' 'SS,' and 'ZI,' represent the 'key strength,' 'key weakness,' 'superfluous strength,' 'zone of irrelevance,' respectively.

In summary, some important results raised are described as follows:

- For the importance degree, the top five important competencies are 'curriculum design and event planning,' 'writing skills,' 'breaking stereotypes,' 'oral communication skills,' and 'file management,' respectively.

- For the relative strength degree, the top five competencies are 'finding problems,' 'flexibility,' 'judging knowledge value,' 'transforming knowledge into concrete actions,' and 'knowledge application on work planning,' respectively.

- Eleven core competencies in 'KS' zone include 'finding problems,' 'flexibility,' 'interpersonal communication,' 'oral communication skills,' 'knowledge selection,' 'activities recording,' 'knowledge application on work planning,' 'research data application,' 'transforming knowledge into concrete actions,' 'interpreting results,' and 'judging knowledge value,' respectively.

- Twelve competencies in 'KW' zone include 'examination,' 'conceptual naming,' 'breaking stereotypes,' 'knowledge sharing,' 'curriculum design and event planning,' 'writing skills,' 'file management,' 'knowledge classification,' 'research methods and research data interpretation,' 'knowledge application on solving problems,' 'knowledge application on creating substantial work pieces,' and 'using tools,' respectively.

- Four competencies in 'SS' zone include 'imagination,' 'multimedia usage,' 'creating knowledge database,' and 'knowledge application on resources development,' respectively.

- Six competencies in 'ZI' zone include 'public media usage,' 'understanding market demand,' 'knowledge application on improving organization atmosphere,' 'knowledge application on various circumstances,' 'reviewing knowledge usefulness,' and 'analyzing knowledge cost,' respectively.

Here, more discussions with core competencies of the 'KS' zone can be noted, as follows: 
First, there are two core competencies - 'finding problems' and 'flexibility' - on the 'knowledge innovation' dimension. Baldwin and Hanel (2003) pointed out that the knowledge creation comes from knowledge innovation. Hence, the most important key capability for teachers is possessed of knowledge innovation.

Second, there are two core competencies - 'interpersonal communication' and 'oral communication skills' - on the 'knowledge dissemination' dimension. The dissemination is a process that teachers can make use of their knowledge and experience to finally increase the knowledge value. Hu et al. (2005a) indicated that the most import capability for teachers is possessed of knowledge dissemination. Third, there are also two core competencies - 'knowledge selection' and 'activities recording' - on the 'knowledge accumulation' dimension. The knowledge accumulation indicated that teachers perform their experience in a systematic manner to store up their knowledge and finally to increase the useful knowledge in quality and in quantity.

Fourth, there are three core competencies - 'knowledge application on work planning' 'research data application' and 'transforming knowledge into concrete actions' - on the 'knowledge application' dimension. The knowledge application indicated that teachers can make use of these core competencies to bring the efficiency (i.e. increasing the functional speed) and effectiveness (i.e. accomplishing certain event) in the knowledge management. The knowledge application belonged to the parts of actual operations in their works. Fifth, there are two core competencies - 'interpreting results' and 'judging knowledge value' - on the 'knowledge assessment' dimension. When teachers evaluate the 'true and false' or usefulness after the knowledge dissemination and knowledge application, the knowledge assessment indicated that the rationality of knowledge could be corrected in the necessary.

\section{Conclusion and Recommendations}

This paper aims to evaluate the core competencies of elementary schools' teachers at remote rural area in Taiwan by using the MA approach. To facilitate the main issue for assessing the core competencies, the five aspects with 33 competencies are employed firstly. These important competencies have been discussed and publicized in academic and management fields. Subsequently, the Grant's MA approach is used to measure these competencies. Finally, the systematic appraisal approach is to perform the empirical survey via questionnaires. The empirical results in this paper show that: (1) eleven core competencies are classified as 'KS' zone; (2) twelve competencies are classified as 'KW' zone; (3) four competencies are classified as 'SS' zone; and (4) six competencies are classified as 'ZI' zone, respectively.

This study evaluates the impact points of core competence on knowledge management for elementary schools' teachers in Taiwan. There are eleven core competencies belong to 'KS' zone; however, twelve competencies in 'KW' zone. Here, it is worth to point out, as recommendations of the authors, which the important tasks for the elementary teachers are as follows. 
- Exploit core competencies effectively. How do the teachers exploit core competencies more effectively? As we use the MA approach to rank the priority of these eleven core competencies, the main purpose is to allocate the limited resources and to improve various knowledge management activities in the formulation of strategies for teachers. Hence, it is suggested that more attentions should be paid to develop profile of strategies of eleven core competencies and that implementation should be carried out to outstand their competitors in the elementary schools.

- Improve key weaknesses diligently. What do the teachers do about their key weakness in terms of both upgrading them and managing their vulnerability and disadvantage? The elementary schools' teachers should appraise how they can extend existing competencies on knowledge management, develop new ones, and formulate their strategies to defend against key weakness, or even to transform 'KW' zone into 'KS' zone endlessly.

In summary, our key focus on these implications are as follows: (1) exploiting eleven core competencies effectively in the 'KS' zone; and (2) improving twelve competencies diligently in the 'KW' zone. It is suggested that more attentions should be paid to exploit these core competencies effectively and then develop the solutions, which should continuously strengthen the perspective of teachers in order to obtain the competitive advantages in the future.

\section{Acknowledgements}

The authors gratefully acknowledge the helpful comments and suggestions of the reviewers, which have improved the presentation. Furthermore, the authors would like to thank Dr. Ji-Feng Ding at Chang Jung Christian University for his assistance in the proposed method.

\section{References}

Alavi, M. \& Leidner, D. E. (2001). Review: Knowledge Management and Knowledge Management Systems: Conceptual Foundations and Research Issues. MIS Quarterly, 25(1), 107-136.

Baldwin, J. R. \& Hanel, P. (2003). Innovation and Knowledge Creation in an Open Economy. Cambridge: Cambridge University Press.

Cheng, H. W. (2007). A Study on the Service Quality of Elementary School: Take Taichung as An Example. Master Thesis, Taiwan: Chung Hua University.

Grant, R. M. (2002). Contemporary Strategy Analysis: Concepts, Techniques, Applications (4th ed.). UK: Blackwell Publishers Inc.

Hair, J. F., Black, W. C., Babin, B. J. \& Anderson, R. E. (2010). Multivariate Data Analysis: A Global Perspective ( $7^{\text {th }}$ ed.). New York: Prentice Hall Company.

Hsiao, C. C. \& Hu, M. C. (2007). A Study for Multi-level Analysis of Adult Education Workers' Knowledge Management Abilities: An Application of Hierarchical Linear Model. Educational Review, 29, 1-36. 
Hu, M. C., Hsiao, C. C. \& Lin, H. H. (2005a). A Study of Core Competence as an Adult Educator on the Knowledge Management and the Relationship among Competence, Performance, and Training Needs. Kaohsiung Normal University Journal, 18, 23-43.

Hu, M. C., Hsiao, C. C. \& Wu, T. H. (2005b). A Study on Adult Education Administrators' Knowledge Management Core Competencies, Performance Evaluation, and Training System. Educational Policy Forum, 8(2), 175-210.

Hu, M. C., Hsiao, C. C. \& Wu, T. S. (2006). The Construction of Indicators for the Adult Educators' Core Competences of Knowledge Management. Educational Review, 27, 21-50.

Jones, G. R. \& George, J. M. (2010). Essentials of Contemporary Management (4th ed.). New York: McGraw-Hill Companies.

Kebede, G. (2010). Knowledge Management: An Information Science Perspective. International Journal of Information Management, 30(5), 416-424.

Lee, M. R. \& Chen, T. T. (2012). Revealing Research Themes and Trends in Knowledge Management: From 1995 to 2010. Knowledge-Based Systems, 28, 47-58.

Lu, Y. M. \& Wu, H. H. (2010). Applying IPA in Evaluating Service Quality Requirements of Passengers of Taiwan High Speed Rail. Journal of Quality, 17(1), 21-43.

Newell, S., Robertson, M., Scarbrough, H. \& Swan, J. (2002). Managing Knowledge Work. New York: Palgrave.

Saaty, T. L. (1980). The Analytic Hierarchy Process. New York: McGraw-Hill. 